\title{
HUBUNGAN ANTARA IKLIM KOMUNIKASI ORGANISASI DENGAN KEPUASAN KERJA KARYAWAN PT. PARAMOUNT ENTERPRISE INTERNATIONAL
}

\author{
Ananda Marvian Dwi Nopiyanto, Hanny Hafiar, Syauqy Lukman \\ Fakultas Ilmu Komunikasi, Universitas Padjadjaran \\ anandamarvian@gmail.com
}

\begin{abstract}
Abstrack
The aim of this study is to acknowledge the correlation between organizational communication climate and job satisfaction in PT. Paramount Enterprise International. This study used Human Relation theory abd correlation method with descriptive and inferential statistical analysis. The amount of samples was 52 people which was obtained by simple random sampling technique. The data was obtained by questionnaire, interview, and literature review. The result of this study was that there was strong correlation between organizational communication climate and job satisfaction. The conclusion of this study was that there was strong relationship between trust, making a decision together, honesty, listening to the upward communication, attention to high-performance goals with job satisfaction aspects, and a significant relationship between openness to downward communication and the job satisfaction aspects. Based on these conclusions, the researcher suggests increasing the time intensity of listening to employees and telling them frankly also promising to find and develop a communication plan if the leader does not have the information which the employee needs.
\end{abstract}

Keyword: Human Relation Theory, Organisational Communication Climate, Job Satisfaction.

\begin{abstract}
Abstrak
Penelitian ini bertujuan mengetahui Sejauhmana hubungan iklim komunikasi organisasi dengan Kepuasan Kerja Karyawan di PT. Paramount Enterprise International. Penelitian ini menggunakan teori Hubungan Manusiawi dengan metode korelasional serta teknik analisis data deskriptif dan inferensial. Jumlah sampel sebanyak 52 orang ditentukan melalui teknik simple random sampling. Pengumpulan data dilakukan dengan cara penyebaran angket, wawancara, dan studi pustaka. Hasil penelitian ini ialah terdapat hubungan yang kuat antara iklim komunikasi organisasi dengan kepuasan karyawan. Simpulan dari penelitian ini terdapat hubungan yang kuat antara kepercayaan, membuat keputusan bersama, kejujuran, mendengarkan dalam komunikasi ke atas, perhatian terhadap tujuan-tujuan berkinerja tinggi dengan aspek kepuasan kerja, dan hubungan yang cukup berarti antara keterbukaan terhadap komunikasi ke bawah dengan aspek aspek kepuasan kerja. Berdasarkan simpulan tersebut, peneliti menyarankan agar meningkatkan intesnsitas waktu untuk mendengarkan karyawan dan mengatakan terus - terang serta berjanji akan mencarikannya dan mengembangkan suatu perencanaan komunikasi Jika pemimpin tidak mempunyai informasi yang dibutuhkan karyawan.
\end{abstract}

Kata kunci: Teori Hubungan Manusiawi, Iklim Komunikasi Organisasi, Kepuasan Kerja. 


\section{PENDAHULUAN}

PT Paramount Enterprise International adalah grup diversifikasi perusahaan yang berbasis di Gading Serpong, Tangerang, Indonesia. Dengan pengembangan real estate perkotaan sebagai inti kegiatan usaha. Berdiri sejak tahun 1992 tidak menutup kemungkinan terjadinya permasalahan pada organisasi sehingga mau tidak mau mengharuskan adanya perbaikan dan pengembangan banyak hal yang berdampak pada kepuasan kerja pada perusahaan.

Permasalahan dalam iklim komunikasi organisasi yang terjadi di PT Paramount Enterprise International tidak serta merta dibiarkan oleh perusahaan. Ada perbaikan-perbaikan yang sudah dilakukan dalam memperbaiki iklim komunikasi organisasi yang terjadi agar terciptanya peningkatan kepuasan kerja yang positif.

Kepuasan kerja merupakan faktor terpenting dan harus dimiliki oleh setiap anggota perusahaan, karena kepuasan adalah implementasi dari sikap positif seorang karyawan terhadap perusahaan tempat ia bekerja. Karyawan cenderung akan merasa puas jika kondisi kerja yang dijalaninya menyenangkan, bukan hanya kondisi fisik perusahaan saja tapi juga hubungan komunikasi verbal dan non verbal yang terjalin dengan rekan sejawat, hubungan antara bawahan dengan atasan maupun atasan dengan bawahan.

Peningkatkan kepuasan kerja akan mempertinggi motivasi kerja dan akan meningkatkan produksi organisasi yang kemudian akan memajukan perusahaan di masa kini maupun yang akan datang.

Meskipun Iklim Komunikasi yang ada di PT. Paramount Enterprise sudah membaik dan kepuasan kerja yang ada di PT Paramount Enterprise International tergolong baik. tidak serta merta menurunkan tingkat turnover yang tinggi .

Hal ini dilihat dari banyaknya tinggkat turnover yang tinggi hingga mencapai sekitar 40 orang per bulan "banyak yang keluar tiap bulannya sekitar 30 orang bahkan tertinggi 40 orang lebih yang kebanyakan berasal dari pegawai lini 1 ini sudah masuk kategori tinggi untuk perusahaan.

Jika terus dibiarkan akan berpotensi membuat tujuan perusahaan tidak tercapai. Terlebih jika kepuasan kerja karyawan terjadi penurunan yang akan berpengaruh terhadap kondisi perusahaan. Untuk meminimalisir permasalahan yang terjadi inilah PT Paramount Enterprise International harus memperbaiki dan berusaha meningkatkan kepuasan kerja karyawan dengan mengelola organisasi yang efektif dan kondusif salah satunya melalui iklim komunikasi yang terjadi dalam organisasi dan kepuasan kerja dalam organisasi.

\section{TINJAUAN PUSTAKA}

Teori yang digunakan adalah Teori Hubungan Manusiawi dari Elton Mayo yang memandang manusia sebagai komponen penting dalam organisasi dan juga pentingnya hubungan sosial antara anggota di dalam organisasi (Muhammad, 2014:40). Teori ini membahas dibalik formalitas organisasi yang terus menekankan bekerja, yakni pengembangan hubungan manusiawi yang baik dalam suatu organisasi

Berdasarkan teori hubungan manusiawi tersebut, maka dapat disimpulkan bahwa dengan meningkatkan 
kepuasan kerja karyawan dan mengembangkan potensi yang mereka miliki maka produksi perusahaan pun akan meningkat dangan mengembangkan potensi , aktualisasi diri karyawan, dan mempertinggi motivasi kerja akan membantu karyawan dalam melakukan tugas-tugas pekerjaannya dalam mencapai tujuan perusahaan. Variabel X : Iklim Komunikasi Organisasi, sedangkan variabel Y : Kepuasan Kerja Karyawan.

Density atau kepadatan juga merupakan salah satu faktor lingkungan kerja yang dapat memperngaruhi kondisi kerja karyawan. Jika kayawan tidak dapat menerima kepadatan yang terjadi maka dapat menimbulkan stress, baliknya jika dapat menerimanya maka karyawan dapat beradaptasi dengan kondii kerjanya.

Rekan kerja yang mendukung menekankan bahwa karyawan bekerja juga untuk mengisi kebutuhan interaksi sosial (Robbins, 2001:150). Interaksi sosial yang dialami oleh seorang karyawan meliputi interaksi dengan rekan sekerja secara horizontal (teman satu divisi / lintas divisi) dan vertikal (atasan dengan bawahan)

\section{METODOLOGI PENELITIAN}

Metode yang digunakan adalah metode penelitian survei dengan teknik korelasional. Penelitian survei adalah penelitian yang mengambil sampel dari suatu populasi dan menggunakan kuesioner sebagai alat pengumpulan data yang pokok (Singarimbun, 2006:3)

Dalam hal ini, hubungan yang dicari adalah hubungan antara variabel Iklim Komunikasi Organisasi dengan Variabel Kepuasan Kerja Karyawan PT. Paramount Enterprise Intenational
Peneliti menetapkan populasi dalam penelitian ini sesuai dengan jumlah karyawan PT.Paramount Enterprise International yang berjumlah 1.407 karyawan dan hanya 826 orang karyawan lini 1 (Data karyawan PT.Paramount Enterprise International Juni 2017)

Untuk menentukan ukuran sampel maka besarnya ukuran sampel dihitung dengan menggunakan Rumus Slovin (Prijana, 2005:8) sehingga diperoleh sampel sebanyak 52 orang karyawan dari total 826 orang karyawan lini 1. Dengan menggunakan teknik simple random sampling, kuisioner disebarkan kepada karyawan melalui email.

\section{HASIL DAN PEMBAHASAN}

Dalam peneitian ini, Iklim komunikasi organisasi (X) diturunkan menjadi beberapa sub-variabel yaitu: . (X1) Kepercayaan, (X2) Pembuatan keputusan bersama, (X3) Kejujuran, (X4) Keterbukaan dalam komunikasi ke bawah, (X5) Mendengarkan dalam komunikasi ke atas, dan (X6) Perhatian pada tujuantujuan berkinerja tinggi. Selanjutnya untuk kepuasan kerja karyawan (Y) di turunkan menjadi 4 sub-variabel yaitu: ( $\left.\mathrm{Y}_{1}\right)$ Pekerjaan yang menantang secara mental, (Y2) Ganjaran yang pantas, (Y3) Kondisi Kerja yang Mendukung, (Y4) Rekan kerja yang mendukung

Analisis korelasi dilakukan dengan menggunakan korelasi Rank Spearman (Spearman's Rank Order) untuk menguji hubungan di antara dua variabel

Dalam menentukan keeratan hubungan, peneliti menggunakan kriteria Guilford sebagai panduan (Rakhmat, 2005:29)

1. $<0,20$

:Hubungan rendah sekali 


$\begin{array}{ll}\text { 2. } 0,20-<0,40 & : \text { Hubungan } \\ & \text { rendah tapi pasti } \\ \text { 3. } 0,40-<0,70 \quad \text { Hubungan yang } \\ \text { cukup berarti } \\ \text { 4. } 0,70-<0,90 \quad \text { Hubungan yang } \\ \text { tinggi, kuat } \\ \text { 5. }>0,90 & \text { :Hubungan yang } \\ & \text { sangat tinggi, } \\ & \text { kuat sekali }\end{array}$

\begin{tabular}{|c|c|c|}
\hline $\begin{array}{c}\text { Variabel/ Sub } \\
\text { Variabel }\end{array}$ & Drs & $\mathbf{t}_{\text {hitung }}$ \\
\hline $\begin{array}{l}\text { Variabel X : iklim } \\
\text { komunikasi } \\
\text { organisasi dengan } \\
\text { Variabel Y : } \\
\text { kepuasan kerja } \\
\text { karyawan PT. } \\
\text { Paramount } \\
\text { Enterprise } \\
\text { International }\end{array}$ & 0,835 & 10,735 \\
\hline $\begin{array}{l}\mathrm{X} 1 \text { :Kepercayaan } \\
\text { dengan Y1 : } \\
\text { Kepuasan Kerja }\end{array}$ & 0,718 & 7,297 \\
\hline $\begin{array}{l}\text { X2 : Pembuatan } \\
\text { Keputusan } \\
\text { Bersama dengan } \\
\text { Y1: Kepuasan } \\
\text { Kerja }\end{array}$ & 0,800 & 9,427 \\
\hline $\begin{array}{l}\text { X3 : Kejujuran } \\
\text { dengan Y1: } \\
\text { Kepuasan Kerja }\end{array}$ & 0,778 & 8,755 \\
\hline $\begin{array}{l}\text { X4:Keterbukaan } \\
\text { terhadap } \\
\text { komunikasi ke } \\
\text { bawah dengan Y1 } \\
\text { : Kepuasan Kerja }\end{array}$ & 0,281 & 2,069 \\
\hline $\begin{array}{l}\text { X5: Mendengarkan } \\
\text { dalam komunikasi } \\
\text { ke atas dengan Y1: } \\
\text { Kepuasan Kerja }\end{array}$ & 0,772 & 8,581 \\
\hline $\begin{array}{l}\text { X6: perhatian } \\
\text { terhadap tujuan- }\end{array}$ & 0,793 & 9,208 \\
\hline
\end{tabular}

\begin{tabular}{|l|l|l|}
$\begin{array}{l}\text { tujuan berkinerja } \\
\text { tinggi dengan Y1: } \\
\text { Konatif }\end{array}$ & \\
Penelitian ini membahas Iklim
\end{tabular} Komunikasi yang ada di PT. Paramount Enterprise sudah membaik dan kepuasan kerja yang ada di PT Paramount Enterprise International tergolong baik. tidak serta merta menurunkan tingkat turnover yang tinggi.

Penelitian ini didasari pada teori hubungan manusiawi (Human Relations Theory) yang dikemukakan oleh Elton Mayo. Berdasarkan asumsi teori tersebut, maka perhatian yang juga merupakan kondisi atau situasi kerja dapat mengubah sikap dan perilaku karyawan. Tak hanya itu, interaksi karyawan satu dengan yang lainnya juga diperlukan untuk meningkatkan moral dan produktifias karyawan.

Teori ini menyarankan strategi peningkatan dan penyempurnaan organisasi dengan meningkatkan kepuasan anggota organisasi. Berdasarkan teori hubungan manusiawi tersebut, maka dapat disimpulkan bahwa dengan meningkatkan kepuasan kerja karyawan dan mengembangkan potensi yang mereka miliki maka produksi perusahaan pun akan meningkat dangan mengembangkan potensi , aktualisasi diri karyawan, dan mempertinggi motivasi kerja akan membantu karyawan dalam melakukan tugas-tugas pekerjaannya dalam mencapai tujuan perusahaan.

Dengan kata lain titik sentral hubungan manusiawi adalah manusia dan titik sentral hubungan manusiawi dalam organisasi adalah karyawan. Untuk mempraktekan hubungan manusiawi kebutuhan karyawan dalam suatu organisasi harus terpenuhi agar dapat meningkatkan kepuasan kerja karyawan 
sehingga terciptanya produktivitas kerja dengan memperhatikan berbagai bentuk komunikasi yang dikembangkan dalam organisasi sehingga menciptakan iklim komunikasi yang baik

Berdasarkan hasil penelitian di atas dapat dilihat bahwa terdapat hubungan antara Kepercayaan $\left(\mathrm{X}_{1}\right)$ dengan kepuasan kerja (Y) dengan derajat koefisien kuat. Hal ini mengindikasi bahwa keeratan hubungan antara kepercayaan dengan kepuasan kerja merupakan hubungan yang kuat sehingga karyawan yakin melakukan berbagai pekerjaan dan memiliki kredibilitas dalam pendelegasian wewenang dari atasan.

Adanya hubungan antara pembuatan keputusan bersama $\left(\mathrm{X}_{2}\right)$ dengan kepuasan kerja (Y) dengan derajat koefisien kuat. Para pegawai di semua tingkat dalam organisasi harus diajak berkomunikasi dan berkonsultasi mengenai semua masalah dalam semua wilayah kebijakan organisasi, yang relevan dengan kedudukan mereka. Keeratan hubungan antara pembuatan keputusan bersama dengan kepuasan kerja merupakan hubungan yang kuat sehingga karyawan mendapat kesempatan berkomunikasi dalam pembuatan keputusan bersama dan mudah dalam berkonsulasi dengan atasan.

Hubugan yang kuat antara kejujuran $\left(\mathrm{X}_{3}\right)$ dengan kepuasan kerja $(\mathrm{Y})$ dengan derajat koefisien kuat. Hal ini mengindikasikan bahwa keeratan hubungan antara kejujuran dengan kepuasan kerja merupakan hubungan yang kuat sehingga karyawan dapat berkomunikasi bebas dengan teman sejawat atau atasan tanpa mengindahkan jabatan.

Hubugan yang cukup berarti antara keterbukaan terhadap komunikasi ke bawah $\left(\mathrm{X}_{4}\right)$ dengan kepuasan kerja $(\mathrm{Y})$. keeratan hubungan antara keterbukaan terhadap komunikasi ke bawah dengan kepuasan kerja yang merupakan hubungan rendah tapi pasti mengakibatkan karyawan terkadang tidak mudah mendapatkan infomasi mengenai tugas yang diberikan atasan dan terkadang tidak mudah mendapatkan infomasi mengenai pekerjaan yang mempengaruhi pengkoordinasian pekerjaan dengan teman sejawat. Kecuali untuk keperluan informasi rahasia, anggota organisasi harus relatif mudah memperoleh informasi yang berhubungan langsung dengan tugas.

Hubungan antara mendengarkan dalam komunikasi ke atas $\left(\mathrm{X}_{5}\right)$ dengan kepuasan kerja (Y) dengan derajat koefisien yang kuat. Hubungan yang kuat antara mendengarkan dalam komunikasi ke atas dengan kepuasan kerja, sehingga atasan selalu mendengarkan saran bawahan dan menganggap penting saran dari bawahan tersebut. Komunikasi ke atas memperkuat apresiasi dan loyalitas karyawan terhdap organisasi.

Hubugan yang kuat antara perhatian terhadap tujuan-tujuan berkinerja tinggi $\left(\mathrm{X}_{6}\right)$ dengan kepuasan kerja $(\mathrm{Y})$. personel di semua tingkat dalam organisasi harus menunjukan komitmen terhadap tujuan-tujuan berkinrja tinggi, produkktivitas tinggi, kualitas tinggi, biaya rendah-demikian pula yang menunjukan perhatian besar pada anggota organisasi lainnya. (Pace dan Faules 2005:159-160). Dengan menunjukan komitmen terhadap tujuan-tujuan berkinrja tinggi dapat meningkatkan kepuasan kerja karyawan dan mengembangkan potensi yang mereka miliki maka produksi perusahaan pun akan meningkat dangan mengembangkan potensi , aktualisasi diri karyawan, dan mempertinggi motivasi kerja akan 
membantu karyawan dalam melakukan tugas-tugas pekerjaannya dalam mencapai tujuan perusahaan. Hal ini terlihat dari keeratan hubungan antara perhatian terhadap tujuan-tujuan berkinerja tinggi dengan kepuasan kerja sehingga karyawan menunjukan komitmen terhadap tujuan berkinerja tinggi dan Setiap karyawan menunjukan perhatian kepada karyawan lainnya.

\section{PENUTUP}

\section{Simpulan}

1. Kepercayaan memiliki hubungan yang kuat dengan Kepuasan Kerja karyawan. Hal ini menunjukan karyawan yakin melakukan berbagai pekerjaan dan memiliki kredibilitas dalam pendelegasian wewenang dari atasan.

2. Pembuatan keputusan bersama memiliki hubungan yang kuat dengan Kepuasan Kerja karyawan. Pemberian kesempatan dalam pembuatan keputusan bersama dan kemudahan dalam berkonsultasi antara atasan dan bawahan dinilai mempengaruhi kepuasan kerja.

3. Kejujuran memiliki hubungan yang kuat dengan Kepuasan Kerja karyawan. kejujuran dalam berorganisasi dengan teman sejawat dan keterusterangan dalam berorganisasi tanpa mengindahkan atasan atau bawahan. dinilai mempengaruhi mempengaruhi kepuasan kerja.

4. Keterbukaan terhadap komunikasi ke bawah memiliki hubungan yang cukup berarti dengan kepuasan karyawan. Komponen kemudahan mendapatkan informasi mengenai tugas yang diberikan atasan dan kemudahan mendapatkan informasi mengenai pekerjaan yang mempengaruhi pengkoordinasian pekerjaan dengan teman sejawat dinilai cukup dapat mempengaruhi kepuasan kerja karyawan. Dimana kemudahan mendapatkan informasi mengenai tugas yang diberikan atasan dan kemudahan mendapatkan informasi mengenai pekerjaan yang mempengaruhi pengkoordinasian pekerjaan dengan teman sejawat dapat menimbulkan tingkat kepuasan kerja karyawan yang tinggi dalam pencapaian tujuan organisasi . Artinya, keterbukaan terhadap komunikasi ke bawah dapat memancing respon atasan untuk berkomunikasi dengan bawahan meskipun belum semua atasan bersedia melakukannya.

5. Mendengarkan dalam komunikasi ke atas memiliki hubungan yang kuat dengan Kepuasan Kerja karyawan, Atasan mendengarkan saran karyawan secara berkesinambungan dan menganggap cukup penting saran karyawan untuk dilaksanakan dinilai dapat mempengaruhi kepuasan kerja karyawan. Dengan komponen Atasan mendengarkan saran karyawan secara berkesinambungan dan menganggap cukup penting saran karyawan untuk dilaksanakan yang baik dapat menimbulkan tingkat kepuasan kerja karyawan yang tinggi dalam pencapaian tujuan organisasi.

6. Perhatian terhadap tujuan-tujuan berkinerja tinggi memiliki hubungan yang kuat dengan Kepuasan Kerja karyawan, komitmen terhadap tujuan berkinerja tinggi dan setiap karyawan menunjukan perhatian terhadap 
karyawan lainnya dinilai dapat mempengaruhi kepuasan kerja karyawan. Dengan komponen komitmen terhadap tujuan berkinerja tinggi dan setiap karyawan menunjukan perhatian terhadap karyawan lainnya yang baik dapat menimbulkan tingkat kepuasan kerja karyawan yang tinggi dalam pencapaian tujuan organisasi

\section{Saran}

Berdasarkan hasil penelitian di lapangan, maka peneliti mengajukan beberapa saran yang diajukan peneliti, yaitu:

1. Sebaiknya tingkat transparansi informasi antara atasan dengan karyawan lebih ditingkatkan lagi. Dengan cara meningkatkan intesnsitas waktu untuk mendengarkan karyawan dan mengatakan terus - terang serta berjanji akan mencarikannya jika pemimpin tidak mempunyai informasi yang dibutuhkan mereka, hal ini bisa dilakukan diluar kegiatan jam kerja seperti gathering, olahraga dan acara internal lainnya. Agar hubungan di antara karyawan dan atasan mendorong terciptanya kedekatan kekeluargaan antara atasan dan bawahan dan terciptanya unit kerja yang padu.

2. Sebaiknya saran dan gagasan karyawan lebih diperhatikan lagi dengan atasan memberikan respons positif terhadap saran atau formasi yang diberikan karyawan dalam memenuhi kinerja karyawan serta atasan dan memberikan karyawan kesempatan untuk menanyakan pertanyaan, mengajukan ide - ide dan saran - saran tentang jalannya organisasi terasuk pekerjaan yang mereka kerjakan hal ini bisa dilakukan saat makan siang bersama yang sekaligus bisa menjadi wadah sharing para pegawainya agar memudahkan atasan untuk dapat mengetahui bagaimana pendapat karyawan mengenai jalannya organisasi dan pekerjaan yang diberikan kepada mereka sehingga terciptanya respons positif yang memacu semangat kerja karyawan dan atasan dapat mengambil keputusan yang efisien.

3. Sebaiknya departemen employee relations berfokus pada hubungan perusahaan dengan karyawan pada semua tingkatan dengan merancang sistem komunikasi yang melibatkan partisipasi semua pihak dalam manajemen berkomitmen dalam menyediakan pekerjaan sehari-hari, kondisi kerja yang baik, kompetisi yang adil, kesempatan untuk mengembangkan meningkatkan kompetensi diri, pengakuan atas pencapaian yang dihasilkan, pengawasan yang baik, kesempatan untuk mengekspresikan diri dan menyediakan keuntungan yang sesuai bagi para karyawannya hal ini dapat dilakukan dengan mengadakan kegiatan pelatihan soft skill dan seminar untuk karyawan, membuat kelompok kegiatan karyawan, membuat serikat pekerja, sosialisasi dan pelatihan untuk manager, mengadakan group diskusi, award untuk karyawan setiap divisi, dan gathering agar manajemen mengetahui apa yang sedang dipikirkan oleh karyawan dan menciptakan komunikasi internal yang efektif di dalam perusahaan. 


\section{DAFTAR PUSTAKA}

Muhammad, Arni. 2008. Komunikasi Organisasi. Jakarta: Bumi Aksara.

Singarimbun, Masri dan Sofian Effendi. 2006. Metode Penelitian Survei. Jakarta: LP3ES.

Pace R. Wayne dan Faules, Dan Editor Deddy Mulyana. 2005. Komunikasi Organisasi Strategi Meningkatkan Kinerja Perusahaan. Bandung: PT Remaja Rosdakarya
Prijana, 2005. Metode Sampling Terapan. Bandung: Humaniora PT.Paramount Enterprise International Juni 2017

Rakhmat, Jalaluddin, 2002. Metode Penelitian Kuantitatif Teori dan Aplikasi. Jakarta: PT Raja Grafindo Persada

Robbins, Stephen P. 2001. Perilaku Organisasi; Konsep, Kontroversi, Aplikasi Jilid I. Jakarta: Prehallindo. 